\title{
Temporality in participation and observation: perspectives from
}

\section{Albania and Georgia}

\author{
By Martin Demant Frederiksen (University of Aarhus)
}

Whereas the notion of time has usually been seen as an analytical concept, this article focuses issues of time and temporality as methodological tools in anthropological fieldwork. Based on empirical examples from Albania and the Republic of Georgia, the article explores issues of observation and participation in relation to time seen objectively as history and change, that is, time passing by leaving various signs of alteration, and time as a subjective experience, that is, the way time is experienced locally.

\section{Introduction: time}

The concept of time has primarily been a subject of study within philosophy. However in recent years it has also begun to make its presence known in social scientific analyses as a means to describe the rhythms and practices of everyday life in different social contexts (Appadurai 2004, James and Mills 2005, Munn 1992). Adam goes so far as to state that time is at the very root of what makes us human (Adam 2006:119). Culture, she says, "arises with and from efforts to transcend the key delimitations of human existence: death, change and the rhythmicity of the physical environment" (ibid).

Throughout the 1980s and 90s several anthropologists began touching upon the advantages (and necessity) of focusing on aspects of time and temporality in anthropological analysis (Fabian 1983, 1991, Rutz 1992, see Frankenberg 1994 for a thorough review of these). In his book Time and the Other, Fabian (1983) pointed to the fact that we in our writing have to incorporate concepts of history and time as a means to portray coevalness between ethnographer and informants, thus avoiding the creation of an ethnographic present that freezes societies in time. In a recent article, Birth sums up Fabian's argument by noting that: "stating that 'The $\mathrm{X}$ are matrilineal' implies that the $\mathrm{X}$ have always been and always will be matrilineal even though all societies change [...]. Thus, the ethnographic present removes the Other from the flow of time and denies the human propensity to change" (Birth 2008:4). (In his article Birth goes on to explore the challenges of the representation of coevalness in anthropology, arguing for a focus on the temporal frames research subjects themselves use to forge coevalness with the ethnographer.)

In this article I pay due respect to these insights in my focus on issues of time and temporality as a methodological tool in our research practice: fieldwork. In many respects time has always been a crucial aspect of anthropological fieldwork. The qualitative method of participating in the everyday life that takes place in a given society throughout a longer period of time is a hallmark of this science (Dresch and James 1999:3). However besides demarcating the period of fieldwork, time can in fact be a central tool during the course of 
research. In this article I consider a few ways in which aspects of time and temporality can be used methodologically in observation and participation. In doing so, I make use of two understandings of time. One concerns time seen objectively as history and change, that is, time passing by, leaving various signs of alteration. The other concerns time as subjective experience. I refer to this as temporality which, following Appadurai, I take to be "the way time is" (Appadurai 2004:65). My approach to temporality is thus phenomenological in the sense that my interest lies in the way time is experienced locally.

One of the fields in which this methodological focus can be particularly useful is in societies that have undergone various forms of social change. As Verdery (1999) has noted, one of the things that is potentially altered in such situations is the understanding of time. (This bears resemblance to Kracauer's notion of "periods disintegrating"; Kracauer 1995). Such a situation, Verdery continues, was immanently present in many countries after the breakup of the Soviet Union. The Soviet system, as well as socialist regimes in the Balkans, was based on a vision of a road towards a communist future - a vision dramatically altered when the Soviet Union disintegrated in 1991. As Yurchak (2006) has aptly phrased it, "everything was forever until it was no more". It is in this empirical context that I take my point of departure.

What follows draws on my fieldwork experiences from the Republic of Georgia in 2006-07, as well as my experience of living in a small town in the Albanian mountains where my wife was doing fieldwork in the autumn of 2007. The article falls into two main parts considering observation and participation respectively, and in relation to these, time as history and time as a social and subjective experience. Part one explores the possibilities of observing signs of social change in the field, both as seen in official representations and in everyday public space. Part two explores issues of subjective time, and the way embedding oneself into daily rhythms and understandings of the way time is can be a central part of ethnographic participation.

Each of the sections within these two parts revolves around empirical examples from both Albania and Georgia. These four sections can be read individually, but they are not meant as full social analyses, and should be taken for what they are: examples. I provide references to my own and others' experiences and descriptions that explore the individual examples and analytical points more thoroughly. Altogether they should hopefully highlight some of the ways in which questions of time and temporality affect and contribute to the anthropological research process.

\section{Observing social change in public spaces}

Anthropologists have long been preoccupied with descriptions of how people seek to create stability in unstable contexts and how social changes inflict upon already established patterns of everyday life. Within the post-Soviet context this has resulted in a range of analyses of the continuities, subtleties and peculiarities of social change which seek to go further than political and economic explanations and analyses of transition (Berdahl 2000:11, Greenhouse 2002). It has been common among these to look not just at the "from" and the "to" of the socalled transition period, but rather on what is in-between. Almost two decades have passed since the fall of the Soviet Union and the totalitarian regimes in the Balkans, and rather than speaking of a swift transition from communism to market economy, this has more been a period in its own right, marked by what I have elsewhere referred to as a situation of stable instability (Frederiksen 2007b: 51). Said differently, it has been a period in which continuous social change has been immanent. Verdery has shown that the visibility of these changes 
became much used in politics during the 1990s. Most notorious was the removal of statues of Lenin and Stalin from public squares in the former Soviet Union, while in the Balkans, statues of Hoxha and Tito were torn down (Verdery 1999:5, see also De Waal 2007:138). Such statues had once symbolised the timelessness of a regime that today is no more. Tearing down statues thus became a virile and clearly visible sign of change and new times arising. It was a public re-evaluation of the past and a signalling of steps being taken towards the future (Verdery 1999:20). As Yampolsky has similarly argued, this kind of iconoclasm can be seen as a replacement of one period with another. In this sense, monuments have a unique influence on the structure of time (Yampolsky 1995:95, 98).

Verdery and Yampolsky's observations concern the ways in which certain events - such as official reburials and the building and tearing down of official monuments - can be seen as examples and representations of change. In the following section I seek to take this a step further by exploring how social changes can equally be read on more minute levels in everyday social spaces such as museums, cemeteries, cafés and sidewalks. In doing so I suggest that observing what is not there can tell us as much as looking at what is. Hence, while the first example revolves around observing what is represented in public space in Georgia, the second revolves around observing what is missing in public space in a small Albanian town.

\section{Representations of change and non-change in post-revolution Georgia: painting facades}

After gaining independence from the USSR in 1991, the Republic of Georgia was thrown into civil war. Paired with this the 1990s in Georgia came to be signified by socioeconomic decline and corruption within much of the political sphere. Due to accusations of ballot-fraud and corruption the then residing government was overthrown in late 2003 during the socalled "Rose Revolution". The revolution in itself was for many a symbol of change, and although no statues were torn down following the revolution, official representations seeking to show that changes were actually taking place were abundant in the time that followed. In 2004 the leader of the revolution - the young lawyer Mikhail Saakashvili - was elected president. (Saakashvili was elected with over 90 percent of the votes behind him in the January 2004 elections. In early 2008 he was re-elected, this time with little over 50 percent of the voters supporting him.) Shortly after the 2004 elections, a new national flag and a new national anthem was introduced and street names and public holidays were altered. The flag and anthem, as well as the street names, often referred to ancient Georgian symbols and national figures, which, borrowing a phrase from Pelkmans (2006), neutralised the Soviet period in that previous influences on naming and official symbols were removed. Furthermore, in the major cities EU flags began to appear alongside the Georgian flags on all official buildings, signalling a renewed effort to link the country with Europe rather than Russia or the Middle East. Building facades in the centre of the capital Tbilisi were painted in order to appear attractive when foreign officials visited, and beggars and street vendors where cleared from the main avenues (Frederiksen 2007a). It was not that the Soviet period became irrelevant, but more that its symbols were purposefully made redundant.

However, rather than representing changes that would actually improve people's lives, many of these alterations soon came to be looked upon by the general public as representations of the fact that things were not changing at all. (For a similar observation in Astana, Kazakhstan, see Buchli 2007.) For instance, while the facades of houses in central Tbilisi were painted the backs of the houses were not, and the new names and flags hardly changed the 
socioeconomic situation. People continued to be poor and many felt that the changes the government was putting in place did not concern them or help them. As one of my informants ironically stated, he was pleased that the facades of central Tbilisi were being painted in the sense that "at least the painters will have jobs then". For him personally it did not do anything.

I was doing fieldwork in a local NGO at this time, exploring official representations of the future of Georgia and various government reforms that sought to implement the visions of the "Rose-government". What I wanted to examine was how these governmental visions of the future affected the room for manoeuvre of local NGOs working in the development sphere, and how these visions were negotiated and interpreted at a local NGO level. The general perception in the various NGOs I had contact with was that the speed with which the government sought to create changes often ended up slowing down the process (Frederiksen 2007b:35). The feeling was one of continuous contingency and fears that if long term plans were made they were bound to fail due to some change of policy or ministers within the government. As one informant expressed it: "governments come, governments go, and everything stays the same". One way in which people expressed such concerns was by referring to the superficiality of the changes that were made in public space. Tracing the changes in public spaces as well as talking to my informants about them thus became a central part of my fieldwork. Quite literally, I was continuously observing "what is here today that wasn't here yesterday", and this was an essential methodological tool for me.

The social and political situation in Georgia bears similarities to the one found in Albania. Not only do the two countries share a similar past in terms of socialist regimes, they have both experienced severe socioeconomic changes, civil war and increased poverty in the aftermath of independence. As mentioned in the introduction, the act of observing what is present and what appears from day to day in public spaces in a context of dramatic social change has its counterpart in the act of observing what is lacking. The following section is about missing apples and missing museum exhibits in a small Albanian town.

\section{Everyday reminders of change in Albania: missing apples and missing exhibits}

Burrel is located in central Albania, in one of the poorest areas in the country. With perhaps 18,000 inhabitants - the number varies considerably depending on source and season - it is the biggest town in the Mat region. Burrel was once known as "the city of apples", as apple trees stood side by side along many town streets. It is supposed to have been a beautiful sight, especially during spring when they would blossom and in the autumn when thousands of apples would be ripe. What is striking when walking the streets of Burrel today is that there is hardly an apple tree to be found.

In the same way as the rest of Albania, Burrel was seriously affected by the dictatorship of Enver Hoxha and later by the civil unrest that followed the breakdown of the infamous pyramid banking schemes in 1997. During these times, large quantities of the state-owned forest that covered most of the country was illegally cut down, either for private use as firewood or to sell in order to make a living. According to several personal accounts, illegal timbering was comparatively speaking a good business. However, in periods of increased societal instability, moving too far outside of town in order to cut wood involved some risk of getting caught in crossfire. Hence, in order to get hold of firewood, many people began cutting down what was nearest their home. In Burrel this included the apple trees.

Apple trees were not the only thing to disappear from Burrel. When I was accompanying my wife during her fieldwork in the town, I had the opportunity to visit the local museum. It had 
been closed to the public for some time due to restorations, but a few local acquaintances managed to convince the museum staff to let us in. The director himself served as a personal guide as we examined the Illyrian artefacts on the first floor. The second floor contained a small series of more recent local dresses, displaying the wide variety of patterns and colours used in the region. These artefacts, however, only filled up a small area of the entire floor. The rest was an unwilling exhibition of very recent history: empty shelves. During the unrest of 1997 large quantities of the museum's archaeological and ethnographic material were looted. The parallel economies and black markets that flourished in these years made such artefacts easy to sell. As a consequence, entire historical periods disappeared from the museum within moments of time.

The lack of apple trees and museum exhibits is of course not what reveals that a conflict has been present. But observations such as these do tell us something about the way life has been while conflict was present. As Pelkmans has noted in a different context, even empty buildings can have a social life (Pelkmans 2006:195). The same holds true for the lack of trees and exhibits in Burrel, in the sense that their absence is part of the way the social setting is experienced and remembered by those who live there. While the visible changes that occurred in Tbilisi in Georgia from 2003 onwards enabled me to look at changing times and everyday processes of social life, so did looking at what was "not there" in Burrel in Albania. The painting of facades, erection of new statues as well as the dilapidation of existing buildings, the emptiness of museums, the lack of apple trees in a city of apples: all these things can serve as a window through which one can look at social change and the way time has passed in a given society. Furthermore, they exemplify the temporal orientations at stake, meaning that they give us a hint as to how (and if) dwelling in the past, living for the moment, or looking into the future intermingles in a particular social setting (cf. Day et al 1999 for a similar argument on living for the moment, and cf. Kracauer 1995 for an argument on how different temporalities can co-exist). The way people talk about such visible alterations, the way they are used and misused, or the way and reason they are being ignored can be valuable vantage points for talking to and interviewing those who live with and among them.

Naturally, observations of the visibility of historical changes alone are not enough in themselves. An understanding of how time and change is understood and experienced locally is equally necessary. This is where the ethnographic method of participation becomes a key feature in the research process.

\section{Subjective time and temporal participation}

Conducting fieldwork often involves both periods of boredom and periods of trying to keep up with what is going on. In other words, the fieldworker needs to find an everyday pace within the field. I refer to this as temporally embedding oneself in the field, which is what this section is about.

Albania and Georgia are both contexts in which time for many people seems to either stand still or revolve around the immediate. Rising unemployment, economic stagnation, recent and current conflict situations and general political instability have created a situation where possibilities are few and the future uncertain. Settling in fields such as these where societal disorder has been recurrent cannot help but affect the fieldworker both as a person and with regards to the data she or he gathers (cf. Greenhouse 2002). Certain factors within the society where the fieldworker carries out the research become part of a process of experiential participation. Jackson (2005) has developed a sophisticated argument for radical 
experientialism in anthropology, that is, a focus on the personal and shared experience of the native informant and the ethnographer. This implies that common feelings towards the same occurrences can be an important part of understanding what goes on in the lives of one's informants, and I would argue that perceptions of temporality are a key aspect of this. As Das notes on the nexus between time and experience, time is experience (Das 2007:98). It is an integral part of everyday life and the way we move within and make sense of our experiences of our surroundings. In the following two sections I offer two examples of this process: one concerns experiences of short-sightedness in the sphere of development aid in Georgia, the other experiences of "killing time" in Albanian cafés.

\section{Learning the lessons of time in Georgia: constant anticipation}

While conducting my fieldwork in the sphere of psychosocial aid in Tbilisi, I became acquainted with numerous international relief workers, consultants and volunteers who for the most part experienced significant problems with the apparent short-sightedness and lack of planning and initiative that from their perspective seemed to be present in local NGOs. In the early stages of my fieldwork I too found it both problematic and frustrating that basic arrangements such as planning a meeting or an interview a few days or even hours ahead seemed almost impossible.

I was doing research on the way perceptions of the future affected strategic planning in a local NGO, and participating in the everyday work carried out in its main office provided me with a personal experience of the way time was perceived and used. In a sense, this was intimately connected with the painting of facades mentioned earlier. The eagerness of the Georgian government to fulfil the promises of change did not only materialise in facades and street names. It was also evident in the substantial number of reforms being drafted and implemented. Many of these concerned the sphere of psychosocial development and therefore also the NGO I worked in. But many of the reforms seemed to have been drafted and implemented a little too quickly, since various reforms often ended up working directly against each other. The general notion that projects involving the government were likely to fail thus became predominant. Still, one of the main objectives of the international donors who supported many of the local NGOs was that the NGOs - as representatives of civil society - should collaborate with various government institutions. The NGOs thus could not avoid involvement with government projects, which made many of them see planning ahead as an impossible task (Frederiksen 2007b:49). However, the scepticism towards planning ahead did not only affect organisational strategic planning, it was equally present in everyday activities such as planning meetings or reaching the office on time in the morning. In some ways we all expected each other to be late or that something would come up to delay us whenever we had something to do. Now, it would have been easy to conclude that one simply had to slow down, change pace, or be lazy in order to adjust to this, but that would be far from the truth. It was not a question of going into a slower rhythm, but rather a question of incorporating a constant anticipation of contingency.

Even though instability and uncertainty can become a routine matter so that it no longer creates a spectacle, this does not mean that it ceases to have an effect. Although it becomes an everyday occurrence, it holds decisive consequences for the way people act and for their room for manoeuvre, in the sense that it contributes to changing the temporal aspect of what is acted towards and upon. As Johnson-Hanks has noted in a different context, uncertainty does not make people act "recklessly without structure, but rather pre-structures their expectations and reactions in a certain way" (Johnson-Hanks 2005:367). In Tbilisi this meant 
not planning too far ahead, but always being ready, and this held true both for organisations and anthropologists.

\section{Sitting in Albanian cafés: killing time effectively}

My personal experience of Albania was one of not really having anything to do. I had recently finished my MA and decided to accompany my wife on her fieldwork in order to have some time to relax and write a few articles. However, an almost constant lack of electricity made the latter somewhat problematic. I was used to writing notes by hand, but entire articles proved more difficult (though, as Caroline Humphrey has drawn to my attention, hand-writing by candlelight like a nineteenth-century scholar is in itself a kind of participant experience of a different temporality). During the long periods without electricity, strolling around the small town and drinking coffee in one of the cafés began to take up most of my time. As it turned out, though, I was not the only one for whom this preoccupation was predominant.

The numerous cafés in Burrel were almost constantly packed with men of all ages. In one sense cafés were a place to take refuge in. In cold periods with no heat inside during the day due to electricity being turned off, a café with a generator was a place much sought after. But besides that there would be the company. During summer most sat around small tables in front of the cafés. Some were sitting in large groups with members coming and going, while others were sitting two and two, or alone waiting for company to pass by. Their activities consisted of drinking coffees, playing various card or board games, telling stories from their youth, or of how they managed to cross the border to Greece as illegal immigrants, and how some were caught in this process and abused in jails. Others discussed problematic politics past and present, while still others - mainly the younger crowd - commented loudly on the few girls who dared to venture by on the pavement. (It is interesting to note her that another thing missing from the cafés was women. For a thorough description of gender divisions in public space in Albania see Frederiksen 2008.)

Many of the men were unemployed, and many of the young men had returned from abroad after brief migratory stays in Greece, the UK or elsewhere. When I was introduced to someone in a café the first thing I was told was often something along the lines of: "You know, I used to work in England - that was a great time." Then, shrugging their shoulders they would continue with: "Now I'm back here, doing nothing." The fact that many of the men were unable to support their families and were without any chance of getting a job was a daunting experience for them. As one unemployed man expressed it: "We can't spend our time on anything, all we can do is try to kill it." The cafés were places where people could meet up and if not actually be able to do anything, at least be able to discuss the fact that they had nothing to do.

As I was also unemployed the same was the case for me. But often I would "kill time" by sitting and reading in the room we had rented in the house of a local family. Curiously, this was seen by many of the locals as "doing nothing" while killing time. Our host almost took pride in taking me out to drink coffee and raki with him and his friends when he came home from work, regardless of whether I was busy writing or reading. Towards the end of our stay in Burrel, it was not uncommon for me to end up going to four or five different cafés during a day for a quick cup of coffee with various old or new acquaintances. With each visit lasting around half an hour this amounted to some time (not including the initial long greetings and the almost ritual fight over being allowed to pay the bill). 
My point in describing this is that "killing time" was not merely waiting for it to pass; it had to be done in certain ways in order to be seen as effective. My form of participation not only helped to gain an understanding of the way time was spent, it also served as a means to recognition from the local men in Burrel; I was learning how to do things. The same held true in the NGO office in Georgia. One day when I complained to one of the employees that I was finding it increasingly difficult to get anything done, since meetings, arrangements and plans always changed at the last minute, she laughed a little and said: "I think you're beginning to understand what it's like to live and work here."

\section{Time as methodology: final remarks}

It could be said that longing for the future becomes a waiting for the future, which is partly true. But only partly. As my study of NGO work in Georgia showed, everyday practices or strategies in situations of social change and uncertainty take place within altered or different temporalities. Put the other way around: in order to study strategies one has to look at temporalities, which the field of anthropology has a unique opportunity and ability to do through its method of participation.

While doing fieldwork in places where both present and future can seem problematic (and in most other places for that matter), one thing distinguishes the fieldworker from his or her informants: that the former at some point leaves. As mentioned in the introduction, although anthropological fieldwork is based on a long-term stay, it is inevitably also framed within a limited period. In most cases the date on which the fieldworker terminates the fieldwork in order to return to her or his university is set. Time influences the relationship between fieldworker and informants; it facilitates the establishment of trust, openness, and friendship. But the end of the fieldworker's time in the field also brings out clearly the fact that the fieldworker and his or her research is set within a different time frame. Being aware of this provides an opportunity to reflect on the importance of time: while the Other should not be placed in a different time altogether, as Fabian (1983) has argued, it is valuable to recognize that the Other may be operating in different or altered temporalities.

Observing and participating in these temporalities can be done in various ways. I have given a few examples of my own intentional and unintentional ways of learning about temporalities in this article. For the disadvantaged or for people who live amidst continuous social change and instability, addressing the future is not easily done. Doing fieldwork among such groups entails spending time with them and noticing what time is used for, for instance as exemplified in the Albanian cafés. And the physical environment in which this waiting is done has many stories to tell - be it in terms of representation or that which is lacking. Spending time is not just spending time. Everyday strategies, actions, and feelings are all informed by the temporalities at stake.

\section{References}

Adam, Barbara. 2006. Time. Theory, Culture and Society 23(2-3), 119-138.

Appadurai, Arjun. 2004. The capacity to aspire - Culture in terms of recognition. In Culture and public action (eds.) Vijayendra Rao and Michael Walton, 59-83. Stanford: Stanford University Press. 
Berdahl, Daphne. 2000. Introduction: An anthropological perspective on postsocialism. In Altering states: Ethnographies of transition in Eastern Europe and the former Soviet Union (ed.) Daphne Berdahl, 1-14. Michigan: University of Michigan Press.

Birth, Kevin. 2008. The creation of coevalness and the danger of homochronism. Journal of the Royal Anthropological Institute 14(1), 3-20.

Buchli, Victor. 2007. Astana: Materiality and the city. In Urban life in post-Soviet Asia (eds.) Catherine Alexander, Victor Buchli and Caroline Humphrey, 41-69. London: UCL Press.

Das, Veena. 2007. Thinking of time and subjectivity. In her Life and words: Violence and the descent into the ordinary, 95-108. Berkeley: University of California Press.

Day, Sophie, Akis Paptaxiarchis and Michael Stewart, eds. 1999. Lilies of the field: Marginal people who live for the moment. Boulder and Oxford: Westview Press.

De Waal, Clarissa. 2007. Albania today: A portrait of post-communist turbulence, $2^{\text {nd }}$ ed. London: I.B. Taurus.

Dresch, Paul and Wendy James. 1999. Introduction: Fieldwork and the passage of time. In Anthropologists in a wider world (eds.) Paul Dresch and Wendy James, 1-25. New York: Berghahn Books.

Fabian, Johannes. 1983. Time and the other: How anthropology makes its object. New York: Columbia University Press.

1991. Time and the work of anthropology. Routledge.

Frankenberg, Ronald. 1994. Anthropology and the politics of time. Time \& Society 3(1), 117128.

Frederiksen, Martin Demant. 2007a. Invisible suffering: Mental illness, social annihilation and violence in Georgia. KONTUR 14, 47-53.

-------- 2007b. Blurred visions: Managing and imagining state, strategy and instability in a Georgian NGO. Field report, Department of Anthropology and Ethnography, University of Aarhus.

Frederiksen, Rikke Elisabeth 2008. På vej mod fremtiden - En antropologisk undersøgelse af albanske gymnasieelevers valg af videregående uddannelse [Towards the future - An anthropological examination of Albanian high school students' choices of higher education]. MA thesis, Department of Anthropology and Ethnography, University of Aarhus.

Jackson, Michael. 2005. Existential anthropology: Events, exigencies and effects. New York and Oxford: Berghahn.

James, Wendy and David Mills. 2005. The qualities of time: Anthropological approaches. Oxford: Berg.

Johnson-Hanks, Jennifer. 2005. When the future decides: Uncertainty and intentional action in contemporary Cameroon. Current Anthropology 46(3), 363-385.

Kracauer, Siegfried. 1995. History: The last things before the last. Princeton: Markus Wiener Publishers. 
Munn, Nancy D. 1992. The cultural anthropology of time: A critical essay. Annual Review of Anthropology 21, 93-123.

Pelkmans, Mathijs. 2006. Defending the border: Identity, religion and modernity in the Republic of Georgia. Ithaca and London: Cornell University Press.

Rutz, Henry. 1992. The politics of time. Washington, DC: American Ethnological Monograph Series, AAA.

Verdery, Katherine. 1999. The political lives of dead bodies: Reburial and postsocialist change. New York: Columbia University Press.

Yampolsky, Mikhail. 1995. In the shadow of monuments: Notes on iconoclasm and time. In Soviet hieroglyphics: Visual culture in late twentieth century Russia (ed.) Nancy Condee, 93-113. Bloomington and Indianapolis: Indiana University Press.

Yurchak, Alexei. 2006. Everything was forever, until it was no more: The last Soviet generation. Berkeley: Princeton University Press.

\section{Acknowledgements}

I owe my thanks to Prof. Caroline Humphrey, Rikke Elisabeth Frederiksen and the two anonymous reviewers at Anthropology Matters for valuable critique and comments on this article.

\section{About the author}

Martin Demant Frederiksen is a PhD candidate in the Department of Anthropology and Ethnography, University of Aarhus, Denmark. He is currently working on a project on time, agency and materiality among marginalised male youth in the Autonomous Republic of Ajara in Western Georgia. He can be contacted at etnmdf@hum.au.dk 